\title{
Impacts of external rotators and the ischiofemoral ligament on preventing excessive internal hip rotation: a cadaveric study
}

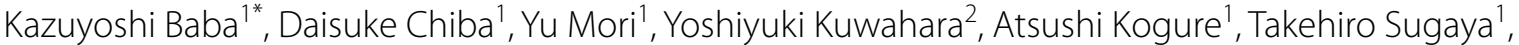 \\ Kumi Kamata ${ }^{3}$, Itsuki Oizumi ${ }^{3}$, Takayuki Suzuki ${ }^{1}$, Hiroaki Kurishima' ${ }^{1}$ Soshi Hamada' ${ }^{1}$ Eiji Itoi ${ }^{4}$ and \\ Toshimi Aizawa ${ }^{1}$
}

\begin{abstract}
Background: This study examined the biomechanics of preventing excessive internal hip joint rotation related to the hip flexion angle.

Method: An intramedullary nail with a circular plate equipped with a protractor was installed in the femur of nine normal hips. The circular plate was pulled by $3.15 \mathrm{Nm}$ of force in the internal rotation direction. The external rotators were individually resected, finally cutting the ischiofemoral ligament. The cutting order of the external rotators differed on each side to individually determine the internal rotation resistance. The external rotators were resected from the piriformis to the obturator externus in the right hips and the reverse order in the left hips. Traction was performed after excising each muscle and ischiofemoral ligament. Measurements were taken at $0^{\circ}, 30^{\circ}$, and $60^{\circ}$ of hip flexion, and the differences from baseline were calculated.

Results: For the right hip measurements, the piriformis and ischiofemoral ligament resection significantly differed at $0^{\circ}$ of flexion $(p=0.02)$, each external rotator and the ischiofemoral ligament resections significantly differed at $30^{\circ}$ of flexion $(p<0.01)$, and the ischiofemoral ligament and piriformis and inferior gemellus resections significantly differed at $60^{\circ}$ of flexion ( $p=0.04$ and $p=0.02$, respectively). In the left hips, the ischiofemoral ligament and obturator externus, inferior gemellus, and obturator internus resections significantly differed at $0^{\circ}$ of flexion $(p<0.01, p<0.01$, and $p=0.01$, respectively), as did each external rotator and the ischiofemoral ligament resections at $30^{\circ}$ of flexion $(p<0.01)$.
\end{abstract}

Conclusion: The ischiofemoral ligament primarily restricted the internal rotation of the hip joint. The piriformis and obturator internus may restrict internal rotation at $0^{\circ}$ and $60^{\circ}$ of flexion.

Keywords: External rotator, Capsular ligament, Dislocation, Ischiofemoral ligament, Total hip arthroplasty, Cadaveric study, Hip joint

\section{Background}

Total hip arthroplasty (THA) is one of the most successful

*Correspondence: kazuyoshi.baba.e3@tohoku.ac.jp

${ }^{1}$ Department of Orthopedic Surgery, Tohoku University School of Medicine, 1-1 Seiryo-machi, Aoba-ku, Sendai, Miyagi 980-8574, Japan

Full list of author information is available at the end of the article procedures for reducing pain and improving function in patients with hip osteoarthritis. The number of patients undergoing THA is increasing and will likely continue in the future. However, dislocation and loosening after primary THA are serious adverse events. The most common causes of revision THA in the United States are hip dislocation and instability $[1,2]$. Endogenous factors related 
to the patients, the surgeon's skills, and the prosthesis design are factors that induce dislocation [3], as well as mechanical factors, such as the accuracy of the prosthesis setting and soft-tissue balance [4]. However, the optimal soft-tissue balance to prevent hip dislocation has not yet been determined.

The dislocation rate for patients who underwent a posterior surgical approach with capsular ligament repair was lower than patients without capsular ligament repair $[5,6]$. These studies suggested that preserved soft tissues, including the capsular ligament and external rotators, help prevent excessive internal rotation and dislocation. The capsular ligaments of the hip are composed of the iliofemoral, ischiofemoral, and pubofemoral ligaments. Anatomically, the ischiofemoral ligament inserts into the ischium and posteroinferior areas of the acetabular rim and attaches to the posterior intertrochanteric line [7]. The ischiofemoral ligament controls the internal rotation and extension of the hip [8].

In previous cadaveric studies, the ischiofemoral ligament restricted primary internal rotation, particularly for flexion $\geq 30^{\circ}$ and adduction [9]. However, these studies only examined the capsular ligament after removing the muscles around the hip joint. The functional role of the ischiofemoral ligament in restricting internal rotation has not been evaluated with a preserved capsular ligament and external rotator muscles. The synergistic effect of the ischiofemoral ligament and external rotator muscles for internal rotation restraint should be evaluated, as should the factors for preventing excessive internal hip rotation. This study determined the contribution of each external rotator muscle and the ischiofemoral ligament for preventing excessive internal hip joint rotation in relation to the hip flexion angle.

\section{Methods \\ Cadaveric study}

The study protocol was approved by the institutional review board of our institute. A total of ten normal hips (four right and six left hips) obtained from seven fresh-frozen cadavers (six males and one female) were enrolled. The age of the specimens at death ranged from 72 to 89 years (mean, 77.6 years). The pelvis was obtained by transecting the spine between the 4th and 5th lumbar spine, and the femur was cut at the midshaft level. All cadavers were thawed overnight at room temperature. The skin and subcutaneous adipose tissues were removed, but the muscles and capsular ligaments remained intact.

The pelvis was fixed on a wooden plate by inserting K-wires at the anterior superior iliac spine and the ischial tuberosity. The pelvis was stabilized in the lateral decubitus position using a plate (Fig. 1). A Phoenix

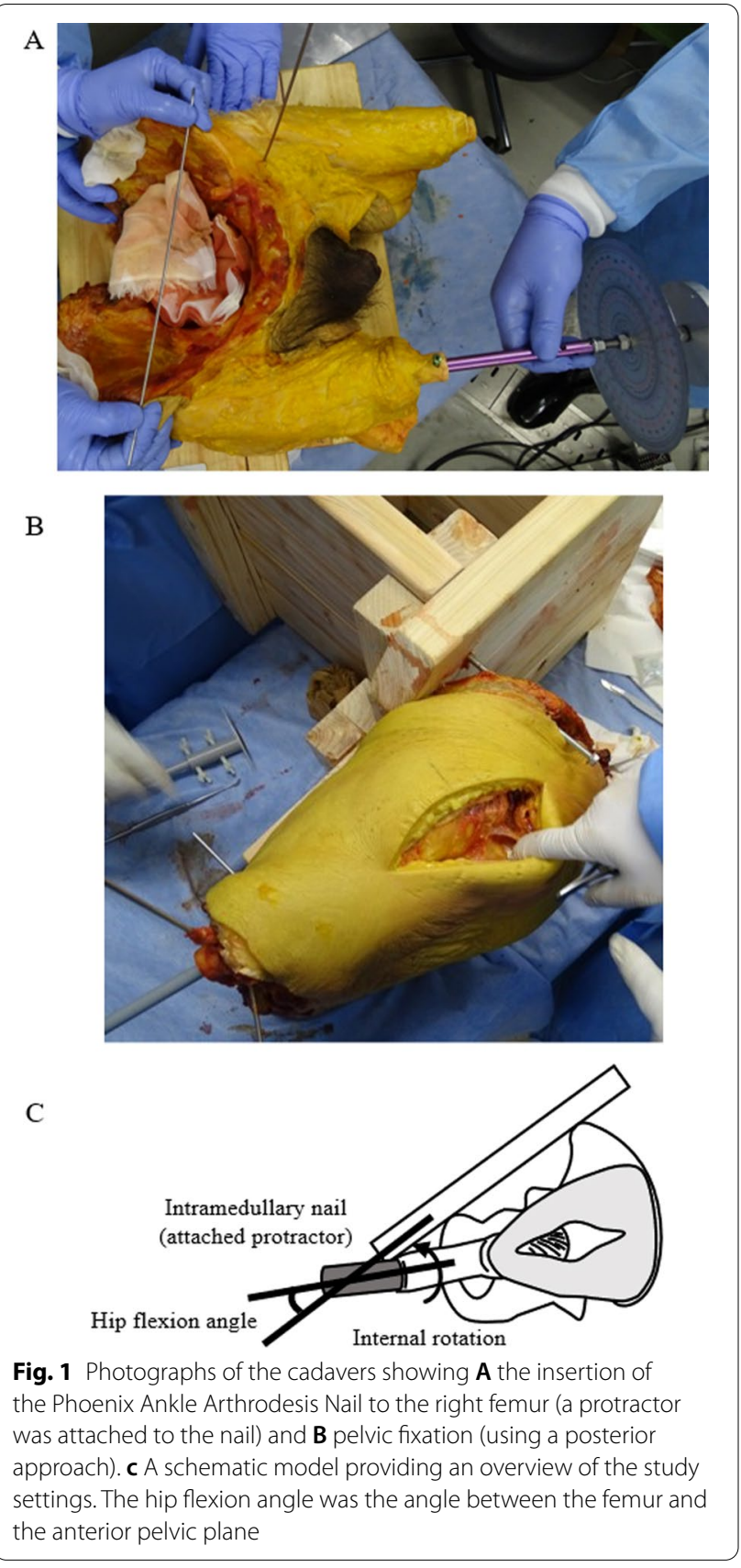

Ankle Arthrodesis Nail (Zimmer Biomet, IN, USA) was inserted into the distal femur and fixed with two screws (Fig. 1). A circular plate (90-mm diameter) with a protractor was fixed $350 \mathrm{~mm}$ away from the center of the femoral head (Fig. 1). The hip center was confirmed using fluoroscopy. With the capsular ligament and external rotators intact, the circular plate was pulled vertically in the direction of internal hip rotation at a constant force of $3.15 \mathrm{Nm}$ applied by a digital pull tension gauge (DST-500 N, IMADA, Japan), then 
A

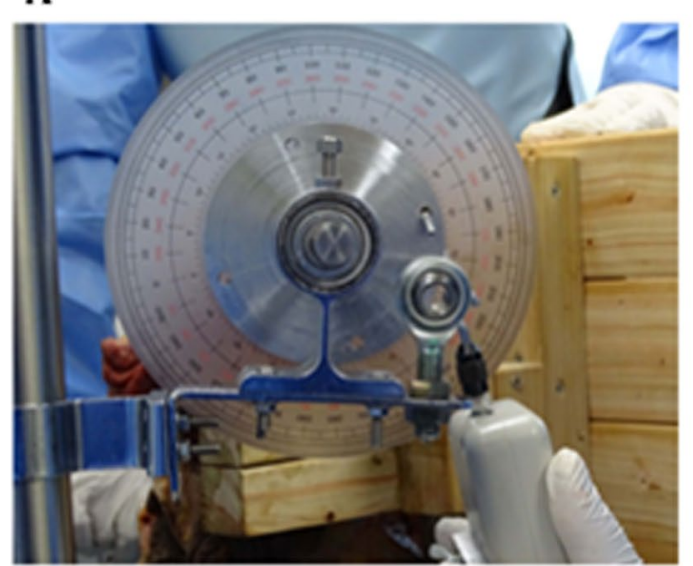

B

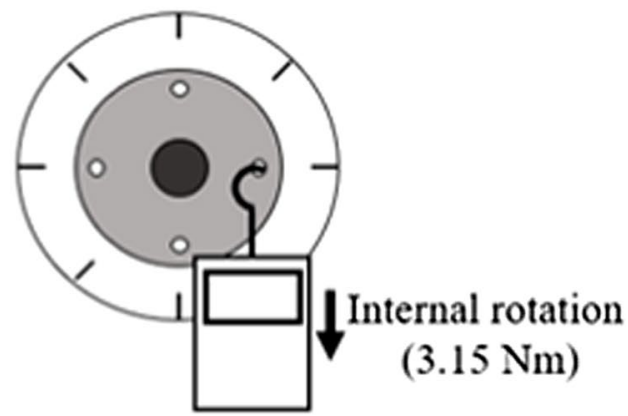

Fig. 2 The angle-measurement method using a digital pull tension gauge. Photographs $\mathbf{A}$ and $\mathbf{B}$ demonstrate the methods used to measure the increasing angles using a digital pull tension gauge

the protractor was photographed (Cyber-shot DSCHX400V, Sony, Japan) (Fig. 2). The protractor indicated an angle between the preserved external rotators and the ischiofemoral ligament, defined as the baseline angle.

The hip was dissected using a posterior approach [10] The external rotators, including the piriformis, superior gemellus, obturator internus, inferior gemellus, and obturator externus, were individually identified. The external rotators were released from the piriformis to the obturator externus in the right hips and the reverse order (from the obturator externus to the piriformis) in the left hips (Fig. 3a, b). The protractor was photographed while a $3.15 \mathrm{Nm}$ internal rotation torque was applied to the hip joint. Measurements were performed at $0^{\circ}, 30^{\circ}$, and $60^{\circ}$ of hip flexion, confirmed with a goniometer (Fig. 1). Finally, the ischiofemoral ligament was resected in an L-shape after resecting all the muscles (Fig. 3c). The acetabular labrum remained intact. The protractor measurement was repeated three times after each release step, and the average angle of the three measurements was recorded. An increase in the rotation angle was calculated as the difference between the baseline angle and the angle after each rotator muscle and the ischiofemoral ligament resection. All procedures were performed on the same day. The angle was measured from the photograph using ImageJ 1.51 software (National Institutes of Health, Bethesda, Maryland, USA). Two hip surgeons with more than ten years of experience independently measured the protractor angles.

\section{Statistical analyses}

The results are presented as averages \pm standard deviations. The coefficient of variation was calculated to determine the preciseness of the measurement using SPSS version 21.0 (IBM Corp., Armonk, NY, USA). Statistical differences in the angle based on the stepwise cuts of external rotators and the capsular ligament were performed using one-way analysis of variance with post hoc by Tukey-Kramer test. Statistical significance was set at $\mathrm{p}<0.05$.

\section{Results}

One hip was excluded because of femur fractures occurring during the procedures; nine hips were used for the analysis. In this study, no hips were dislocated during any of the procedures. The intra-class correlation coefficient of the measurements was 0.98 in the right hips and 0.90 in the left hips, and the angle measurement reproducibility was excellent; these values were almost in perfect agreement [11]. The increases in the angle after the stepwise resections of the external rotators did not differ regardless of the order (Figs. 4 and 5).

In the right hips, the results showed in Table 1 and Fig. 4. The angle measurements significantly differed between the piriformis and ischiofemoral ligament resections at $0^{\circ}$ of flexion $(p=0.02$; Fig. $4 \mathrm{a})$, between each external rotator resection and the ischiofemoral ligament resection at $30^{\circ}$ of flexion (all $\mathrm{p}<0.01$; Fig. $4 \mathrm{~b}$ ), and between the ischiofemoral ligament and piriformis resection and inferior gemellus resections at $60^{\circ}$ of flexion $(p=0.04$ and $p=0.02$, respectively; Fig. $4 c$ ).

In the left hips, the results showed in Table 2 and Fig. 5. The angle measurements significantly differed between the ischiofemoral ligament and obturator externus, inferior gemellus, and obturator internus resections at $0^{\circ}$ of flexion $(\mathrm{p}<0.01, \mathrm{p}<0.01$, and $\mathrm{p}=0.01$, respectively; Fig. $5 \mathrm{a}$ ) and between each external rotator resection and 


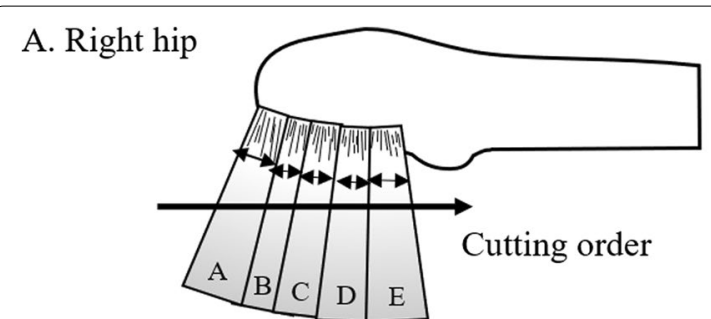

B. Left hip

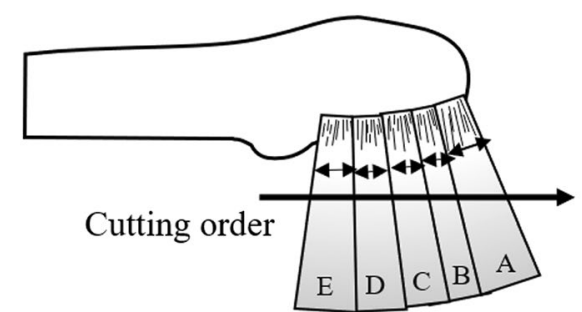

C. Right hip (ischiofemoral ligament was resected)

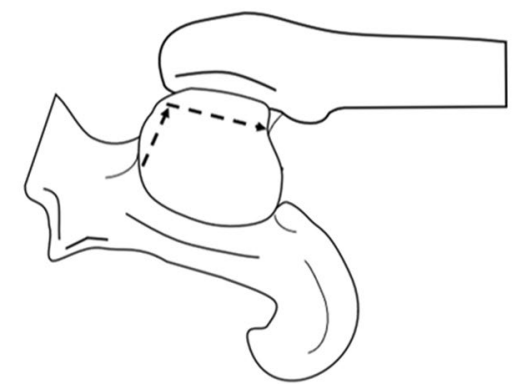

Fig. 3 Schematic models of the stepwise dissections of the hip rotator muscles and ischiofemoral ligament in the posterior hip approach and reverse order. $\mathbf{A}$ The cutting order of the right hip via the posterior approach, indicated by the arrow. $\mathbf{B}$ The cutting order of the left hip in the opposite order from the right hip, indicated by the arrow. $\mathbf{c}$ The cutting order of the ischiofemoral ligament, indicated by the dotted arrow. A, piriformis; B, superior gemellus; C, obturator internus; $D$, inferior gemellus; $E$, obturator externus

the ischiofemoral ligament resection at $30^{\circ}$ of flexion (all $\mathrm{p}<0.01$; Fig. $5 \mathrm{~b}$ ). None of the measurements differed at $60^{\circ}$ of flexion.

\section{Discussion}

This cadaveric study demonstrated that the ischiofemoral ligament primarily restricted excessive internal hip rotation, especially at $30^{\circ}$ of hip flexion. The results also suggest that the external rotators interact synergistically, not individually, to restrict internal rotation at $0^{\circ}$ and $60^{\circ}$ of hip flexion.

The ischiofemoral ligament is one of the posterior capsular ligaments of the hip joint. The ligament is tense during internal rotation and adduction [12, 13]. When the hip is in deep flexion and internal rotation, ischiofemoral ligament tension increases and pulls the femoral head into the acetabulum. The tight ischiofemoral ligament protects against excessive internal hip rotation [9]. A previous study used a CT-based imaging technique to demonstrate that the strain on the hip joint capsular ligament was from an elongated ischiofemoral ligament during hip internal rotation. The ischiofemoral ligament length indicated that the maximum length occurred at a hip flexion of $30^{\circ}$, increasing from $-15^{\circ}$ to $30^{\circ}$, then decreasing from $30^{\circ}$ to $90^{\circ}$ [14]. These anatomical and biomechanical data were consistent with our findings that the ischiofemoral ligament was the primary contributor to hip stability by limiting the internal rotation between $0^{\circ}$ and $60^{\circ}$ of hip flexion, especially at $30^{\circ}$.

Recent reports have emphasized the importance of the ischiofemoral ligament and the external rotators in reducing dislocation risk after THA with a posterior surgical approach [15-17]. However, it was unclear which muscle resisted excessive internal hip rotation, especially at $0^{\circ}$ and $60^{\circ}$ of hip flexion, the ischiofemoral ligament was not stretched. In this study, when cutting from piriformis to obturator externus, the the obturator internus and the obturator externus were important for restricting internal rotation during hip flexion at $0^{\circ}$ and $60^{\circ}$ (Fig. 4a, c). In contrast, the reverse order resection indicated that the piriformis restricted internal hip rotation only at $0^{\circ}$ of hip flexion (Fig. 5a). These results could be explained by changes in the moment arm and the force direction of the external rotators due to the hip flexion angle.

The structural property of the hip external rotators suggested that force generation was maximized to act as a single axis of rotation because its pennation angle was almost parallel [18]. Because of this structural property, the hip external rotators compressed the hip joint along a single axis. However, reports indicated that the moment arm of the external rotators changes depending on the hip flexion angle, which in turn changes the force direction. The moment arm of the piriformis muscle decreased as the hip flexion angle increased and switched from an external to an internal rotation moment arm at approximately $65^{\circ}$ [19]. As a result, the piriformis did not restrict internal rotation at hip flexion angles greater than $60^{\circ}$. However, other reports indicated that the obturator internus and externus restricted internal rotation, even at $90^{\circ}$ of hip flexion $[19,20]$. Therefore, the piriformis functions as an external rotator at $0^{\circ}$ of hip flexion and not at $60^{\circ}$ due to decreased external rotation of the moment arm. Furthermore, the contributions of the obturator internus to restricting internal rotation at $60^{\circ}$ of hip flexion might be more important than the piriformis.

Another important function of the external rotators is dynamic stabilization of the hip joint and performing pelvic and trunk rotational activities while walking 


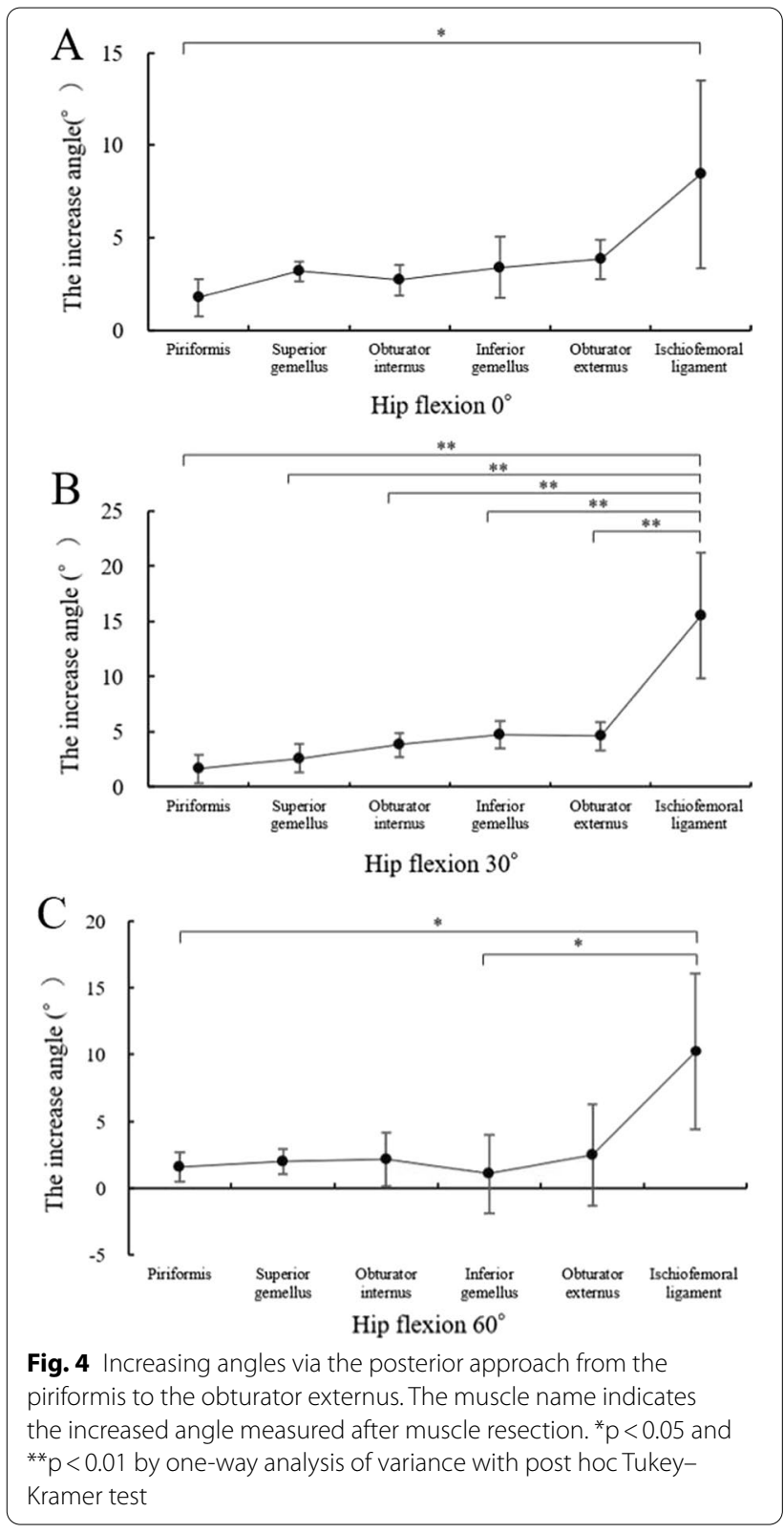

[21]. External rotators might act synergistically in vivo to stabilize the hip joint at any hip flexion angle. An anatomical study of external rotators reported that the superior gemellus, obturator internus, inferior gemellus, and obturator externus were essentially fused [18]. Thus, these external rotators can interact with each other and function as one muscle. The authors considered the possibility that if one muscle was resected, the remaining muscles could compensate to some extent. These findings could explain why the restriction of internal rotation among external rotators in our study did not differ.

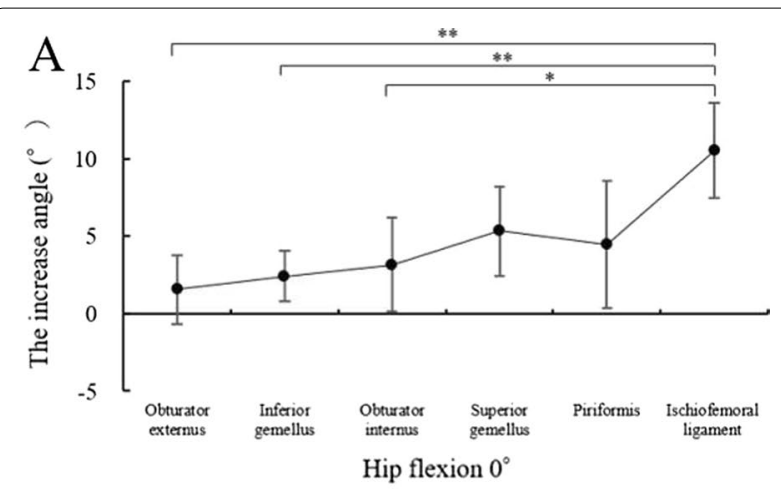

B

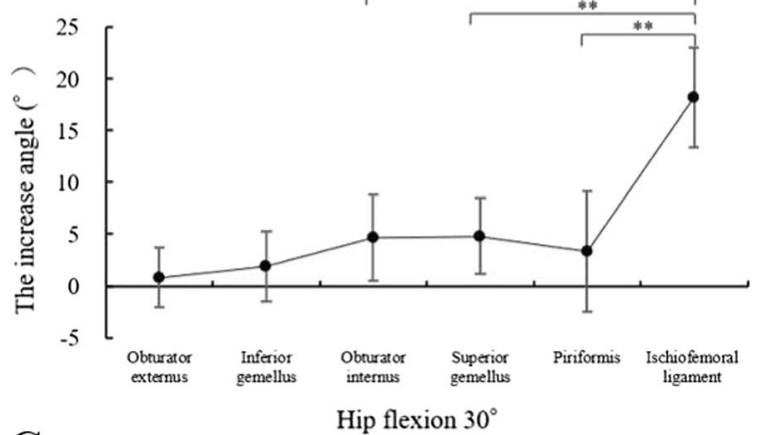

C

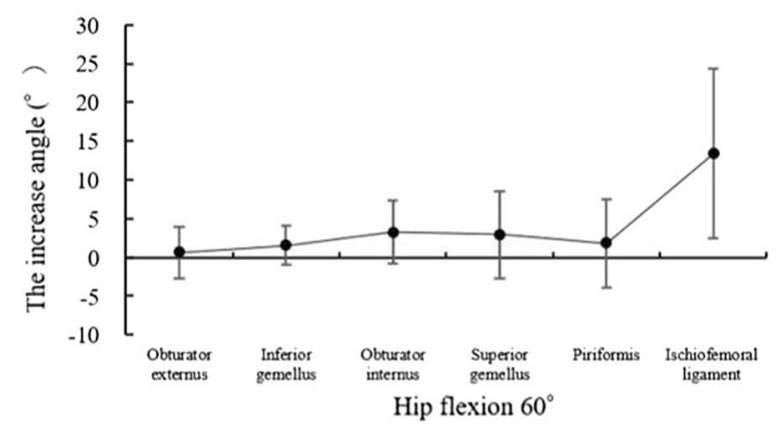

Fig. 5 Increasing angles via the posterior approach from the obturator externus to the piriformis. The muscle name indicates the increased angle measured after muscle resection. ${ }^{*} p<0.05$ and ** $p<0.01$ by one-way analysis of variance with post hoc TukeyKramer test

There were limitations to the present study. First, the sample size was small. Second, the study used cadavers. Therefore, the results could have been influenced by the fact that physiological muscle contraction, including the external rotators, was not possible. Further, the average age of the cadavers in this study was high, and the impact of age-related muscle weakness on the results was debatable. Accumulation of advanced glycation end products in the extracellular matrix with aging is associated with a decline in muscle force transmission in vivo [22], and the strength 
Table 1 Increasing angles via the posterior approach from the piriformis to the obturator externus. The muscle name indicates the increased angle measured after muscle resection. The data are presented as averages \pm standard deviations

\begin{tabular}{lllllll}
\hline & Piriformis & Superior gemellus & Obturator internus & Inferior gemellus & Obturator externus & $\begin{array}{c}\text { Ischiofemoral } \\
\text { ligament }\end{array}$ \\
\hline Hip flexion $0^{\circ}$ & $1.8^{\circ} \pm 1.0^{\circ}$ & $3.2^{\circ} \pm 0.5^{\circ}$ & $2.7^{\circ} \pm 0.8^{\circ}$ & $3.4^{\circ} \pm 1.7^{\circ}$ & $3.8^{\circ} \pm 1.1^{\circ}$ & $8.4^{\circ} \pm 5.1^{\circ}$ \\
Hip flexion $30^{\circ}$ & $1.6^{\circ} \pm 1.3^{\circ}$ & $2.6^{\circ} \pm 1.3^{\circ}$ & $3.8^{\circ} \pm 1.1^{\circ}$ & $4.7^{\circ} \pm 1.3^{\circ}$ & $4.6^{\circ} \pm 1.3^{\circ}$ & $15.5^{\circ} \pm 5.7^{\circ}$ \\
Hip flexion $60^{\circ}$ & $1.6^{\circ} \pm 1.1^{\circ}$ & $2.0^{\circ} \pm 0.9^{\circ}$ & $2.1^{\circ} \pm 2.0^{\circ}$ & $1.1^{\circ} \pm 2.9^{\circ}$ & $2.5^{\circ} \pm 3.8^{\circ}$ & $10.2^{\circ} \pm 5.8^{\circ}$ \\
\hline
\end{tabular}

Table 2 Increasing angles via the posterior approach from the obturator externus to the piriformis. The muscle name indicates the increased angle measured after muscle resection. The data are presented as averages \pm standard deviations

\begin{tabular}{|c|c|c|c|c|c|c|}
\hline & Obturator externus & Inferior gemellus & Obturator internus & Superior gemellus & Piriformis & Ischiofemoral ligament \\
\hline Hip flexion $0^{\circ}$ & $1.6^{\circ} \pm 2.2^{\circ}$ & $2.4^{\circ} \pm 1.6^{\circ}$ & $3.2^{\circ} \pm 3.0^{\circ}$ & $5.3^{\circ} \pm 2.9^{\circ}$ & $4.5^{\circ} \pm 4.1^{\circ}$ & $10.5^{\circ} \pm 3.1^{\circ}$ \\
\hline Hip flexion $30^{\circ}$ & $0.8^{\circ} \pm 2.9^{\circ}$ & $1.9^{\circ} \pm 3.4^{\circ}$ & $4.7^{\circ} \pm 4.2^{\circ}$ & $4.8^{\circ} \pm 3.7^{\circ}$ & $3.3^{\circ} \pm 5.9^{\circ}$ & $18.1^{\circ} \pm 4.8^{\circ}$ \\
\hline Hip flexion $60^{\circ}$ & $0.6^{\circ} \pm 3.4^{\circ}$ & $1.5^{\circ} \pm 2.5^{\circ}$ & $3.2^{\circ} \pm 4.0^{\circ}$ & $2.9^{\circ} \pm 5.6^{\circ}$ & $1.8^{\circ} \pm 5.6^{\circ}$ & $13.3^{\circ} \pm 10.9^{\circ}$ \\
\hline
\end{tabular}

of the external rotators might not be equal between adolescents and older individuals in vivo. In contrast, a previous study comparing the stiffness of cadaveric pelvic floor muscles and obturator internus as controls demonstrated no difference in obturator internus muscle stiffness between adolescents and older individuals [23]. Therefore, age might have a limited effect on studies like ours investigating the prevention of internal hip rotation of external rotators using cadavers. Third, it was not possible to measure $90^{\circ}$ of hip flexion due to the interference of the pelvic fixation device.

\section{Conclusions}

We suggest that excessive internal hip joint rotation is primarily prevented by the ischiofemoral ligament, especially at $30^{\circ}$ of hip flexion. The piriformis and obturator internus together might also restrict internal rotation at $0^{\circ}$ and $60^{\circ}$ of hip flexion.

Abbreviation

THA: Total hip arthroplasty.

\section{Acknowledgements}

Not applicable.

\section{Author contribution}

$\mathrm{KB}, \mathrm{TS}, \mathrm{YK}$, and DC mainly collected the clinical data. KB, YM, and El interpreted the data through discussion. All authors participated in manuscript writing and approved the final version of the manuscript. All authors read and approved the final manuscript.

\section{Funding}

None.

\section{Availability of data and materials}

All data generated or analyzed during this study are included in this published article.

\section{Declarations}

\section{Ethics approval}

This study was approved by the Institutional Review Board of Tohoku University Graduate School of Medicine.

\section{Consent for publication}

Not applicable.

\section{Competing interests}

The authors declare that they have no competing interests.

\section{Author details}

${ }^{1}$ Department of Orthopedic Surgery, Tohoku University School of Medicine, 1-1 Seiryo-machi, Aoba-ku, Sendai, Miyagi 980-8574, Japan. ${ }^{2}$ Sendai City Hospital, 1-1-1 Asuto Nagamachi, Taihaku-ku, Sendai, Miyagi 982-8502, Japan. ${ }^{3}$ Iwaki Medical Center, 16 Kusehara, Uchigo Mimayamachi, Fukushima, Iwaki 973-8555, Japan. ${ }^{4} T o h o k u$ Rosai Hospital, 4-3-21, Dainohara, Aoba-ku, Sendai, Miyagi 981-8563, Japan.

Received: 14 July 2021 Accepted: 5 December 2021

Published online: 04 January 2022

References

1. Bozic KJ, Kurtz SM, Lau E, Ong K, Vail TP, Berry DJ. The epidemiology of revision total hip arthroplasty in the United States. J Bone Joint Surg. 2009;91(1):128-33.

2. Gwam CU, Mistry JB, Mohamed NS, Thomas M, Bigart KC, Mont MA et al. Current epidemiology of revision total hip arthroplasty in the United States: national Inpatient Sample 2009-2013. J Arthroplasty. 2017;32(7):2088-92.

3. Brooks PJ. Dislocation following total hip replacement: causes and cures. Bone Joint J. 2013;95-B(1111 Suppl A):67-9.

4. Dorr LD, Wolf AW, Chandler R, Conaty JP. Classification and treatment of dislocations of total hip arthroplasty. Clin Orthop Relat Res. 1983:173:151-8

5. Chivas DJ, Smith K, Tanzer M. Role of capsular repair on dislocation in revision total hip arthroplasty. Clin Orthop Relat Res. 2006;453:147-52.

6. White RE Jr, Forness TJ, Allman JK, Junick DW. Effect of posterior capsular repair on early dislocation in primary total hip replacement. Clin Orthop Relat Res. 2001;393:163-7.

7. Ng KCG, Jeffers JRT, Beaulé PE. Hip joint capsular anatomy, mechanics, and surgical management. J Bone Joint Surg. 2019;101(23):2141-51. 
8. Martin HD, Savage A, Braly BA, Palmer IJ, Beall DP, Kelly B. The function of the hip capsular ligaments: a quantitative report. Arthroscopy J Arthrosc Related Surg. 2008;24(2):188-95.

9. van Arkel RJ, Amis AA, Cobb JP, Jeffers JR. The capsular ligaments provide more hip rotational restraint than the acetabular labrum and the ligamentum teres: an experimental study. Bone Joint J. 2015;97-B(4):484-91.

10. Moore AT. The Moore self-locking Vitallium prosthesis in fresh femoral neck fractures: a new low posterior approach (the southern exposure). Instr Course Lect. 1959;16:309.

11. Landis JR, Koch GG. The measurement of observer agreement for categorical data. Biometrics. 1977;33(1):159-74.

12. Fuss FK, Bacher A. New aspects of the morphology and function of the human hip joint ligaments. Am J Anat. 1991;192(1):1-13.

13. Wagner FV, Negrão JR, Campos J, Ward SR, Haghighi P, Trudell DJ, et al. Capsular ligaments of the hip: anatomic, histologic, and positional study in cadaveric specimens with MR arthrography. Radiology. 2012;263(1):189-98.

14. Burkhart TA, Baha P, Blokker A, Petrov I, Holdsworth DW, Drangova M, et al. Hip capsular strain varies between ligaments dependent on both hip position- and applied rotational force. Knee Surgery Sports Traumatol Arthrosc. 2020;28(10):3393-9.

15. Gérard R, Savéan J, Lefèvre C. Minimally invasive posterolateral hip approach with SPARTAQUUS (Spare the piriformis And Respect The Active quadratus femoris and gluteus medius) technique. OTSR. 2020;106(8):1523-6.

16. Hanly RJ, Sokolowski S, Timperley AJ. The SPAIRE technique allows sparing of the piriformis and obturator internus in a modified posterior approach to the hip. Hip Int J Clin Exp Res Hip Pathol Therapy. 2017;27(2):205-9.

17. Pellicci PM, Bostrom M, Poss R. Posterior approach to total hip replacement using enhanced posterior soft tissue repair. Clin Orthop Relat Res. 1998:355:224-8.

18. Parvaresh KC, Chang C, Patel A, Lieber RL, Ball ST, Ward SR. Architecture of the short external rotator muscles of the hip. BMC Musculoskelet Disord. 2019;20(1):611.

19. Vaarbakken K, Steen H, Samuelsen G, Dahl HA, Leergaard TB, Nordsletten $L$, et al. Lengths of the external hip rotators in mobilized cadavers indicate the quadriceps coxa as a primary abductor and extensor of the flexed hip. Clin Biomech (Bristol, Avon). 2014;29(7):794-802.

20. Delp SL, Hess WE, Hungerford DS, Jones LC. Variation of rotation moment arms with hip flexion. J Biomech. 1999;32(5):493-501.

21. Neumann DA. Kinesiology of the hip: a focus on muscular actions. J Orthop Sports Phys Ther. 2010;40(2):82-94

22. Wood LK, Kayupov E, Gumucio JP, Mendias CL, Claflin DR, Brooks SV. Intrinsic stiffness of extracellular matrix increases with age in skeletal muscles of mice. J Appl Physiol. 2014;117(4):363-9.

23. Burnett LA, Cook M, Shah S, Michelle Wong M, Kado DM, Alperin M. Ageassociated changes in the mechanical properties of human cadaveric pelvic floor muscles. J Biomech. 2020;98:109436.

\section{Publisher's Note}

Springer Nature remains neutral with regard to jurisdictional claims in published maps and institutional affiliations.

Ready to submit your research? Choose BMC and benefit from:

- fast, convenient online submission

- thorough peer review by experienced researchers in your field

- rapid publication on acceptance

- support for research data, including large and complex data types

- gold Open Access which fosters wider collaboration and increased citations

- maximum visibility for your research: over $100 \mathrm{M}$ website views per year

At BMC, research is always in progress.

Learn more biomedcentral.com/submissions 